\title{
The financial impact of hospital closures on surrounding hospitals
}

\author{
Ashley Hodgson *1, Paul Roback ${ }^{2}$, Andrew Hartman ${ }^{3}$, Erin Kelly ${ }^{4}$, Yujie Li ${ }^{5}$ \\ ${ }^{1}$ Department of Economics, St. Olaf College, United States \\ ${ }^{2}$ Department of Statistics, St. Olaf College, United States \\ ${ }^{3}$ Health Care Futures, United States \\ ${ }^{4}$ United Health, United States \\ ${ }^{5}$ University of California, Berkeley, United States
}

Received: January 24,2015

DOI: $10.5430 /$ jha.v4n $3 p 25$
Accepted: March 24, $2015 \quad$ Online Published: April 1, 2015

URL: http://dx.doi.org/10.5430/jha.v4n3p25

\begin{abstract}
Objective: To test whether hospital closures hurt or help surrounding hospitals financially. Do hospital closures improve market efficiency or do they merely shift the least profitable patients to hospitals that can better cross-subsidize them?

Methods: Using California hospital data from 2000 to 2011, the analysis employed random-effect and fixed-effect models to test for a change in operating margin before and after a series of 2004, 2007 and 2009 hospital closures (the highest volume years for closures). The main independent variable was each hospital's predicted percent increase in patient volume due to absorption from closing hospitals. We used 5-digit zip code and DRG patient flow data to predict the number of patients each open hospital would absorb from nearby hospital closures.

Results: Hospitals experiencing the biggest increase in patient volume due to nearby hospital closings saw a drop in operating margin following those closures. This drop could not be explained by changes in payer mix or reimbursement type for those patients.

Conclusions: Our results suggest that hospital closures are shifting high cost patients to open hospitals, not necessarily improving efficiency in the market.
\end{abstract}

Key Words: Hospital closings, Health care costs, Cost-shifting

\section{INTRODUCTION}

Do hospital closures improve efficiency or do they merely shift the least profitable patients to other hospitals that can better cross-subsidize them? Unlike in other industries, hospitals can linger on the verge of failure for many years, either relying on government support or reducing quality to stay afloat. ${ }^{[1]}$ During this time, the failing hospitals frequently make pleas to local governing boards, arguing that they are not in danger because of inefficiencies but instead because of an obligation to treat patient groups that hurt their bottom line. For example, a 2007 testimony from the President and CEO of the Hospital Alliance of New Jersey to the Commission on Rationalizing Healthcare Resources said, "The easiest way to become more efficient is to be selective about which patients you serve and only treat those for which you will receive proper payment. This 'efficiency' option is not open to hospitals". ${ }^{[2]}$ When states resist hospital cries for a bail-out, they sometimes argue that hospital closures may improve efficiency. A document published by the State of Massachusetts indicated that the state had taken the stance

*Correspondence: Ashley Hodgson; Email: hodgsona@stolaf.edu; Address: Department of Economics, St. Olaf College, United States. 
of encouraging closures among failing hospitals as a way of promoting survival of the fittest among hospitals. ${ }^{[3]}$

When hospitals complain that they are penalized for taking the least profitable patients, two effects are at play: a revenue effect and a cost effect. Readily available data can tell policymakers when a hospital treats an unusually high share of patients with poor reimbursement: Medi-Cal patients, the uninsured, and populations that generally receive uncompensated care. What is less easily observable in the data is the expected cost of treating a particular group of patients, conditional on reimbursement. It is difficult to know if the hospital's high costs are due to inefficiencies or simply the fact that a particular patient group would be high cost no matter which hospital treated them.

We use a two stage process to test the financial impact hospitals experience when they absorb patients from closed hospitals. In the first stage, we use the patients' 5-digit zip codes and DRGs to predict the number of patients each surrounding hospital would absorb from the California hospitals that closed in 2004, 2007 and 2009. These years had the highest number of patients impacted by closures, as shown in Figure 1. We distributed patients from the closing hospitals to open hospitals based on the assumption that historical patient proportions within a zip code attending each hospital would be the same except for the closed hospitals. In the second stage of our analysis, we use both random effects and fixed effects models to look at the change in hospitals' operating margins before and after the hospital closings.

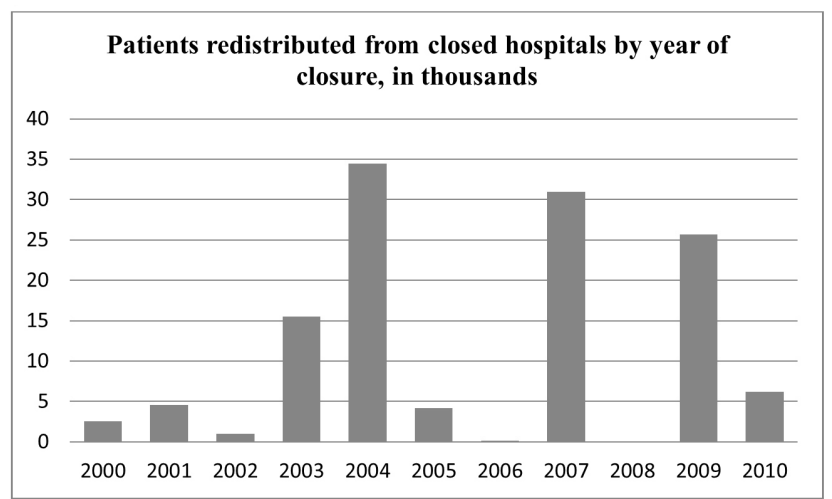

Figure 1. Count of patients that would need to be rerouted to new hospitals based on each year's hospital closures

We found a drop in the operating margin immediately after hospital closures for not-for-profit hospitals predicted to absorb a high number of patients from closing hospitals. We found no evidence of this effect on for-profit hospitals. At the same time, absorption of these patients was not associated with a major change in payer mix of patients; hospitals had similar percentages of Medicare, Medi-Cal and privately insured patients before and after absorbing the new patients. This indicates that the cost effect may be more important than the revenue effect for hospitals absorbing patients from closing hospitals.

Our results support the notion that a large portion of highcost patients, conditional on reimbursement, may at least partly explain the reason for hospital closures and the impact on surrounding hospitals. In which case, shifting these patients to open hospitals may not lead to an improvement in efficiency, but merely a shifting of costs.

\section{Review of literature and conceptual framework}

Several different forces could influence a hospital's financial condition when absorbing patients from closed hospitals (see Table 1). The first of these is the market power effect, which is a hospital's improved bargaining power from the increase in market share they enjoy when a competitor closes. When hospitals experience an increase in market share due to consolidation, they are able to raise prices, often substantially. ${ }^{[4]}$ In addition to driving up hospital prices, better negotiation power within hospitals can also render lower costs as administrators negotiate with doctors and device-makers over input prices. A number of studies show that $\mathrm{HHI}$ is positively correlated with either price or price growth, although some find no correlation. ${ }^{[4]}$ Also, the Medical Arms Race literature suggests that competition among hospitals increases costs because these hospitals compete by buying unnecessary and expensive technology in order to attract patients. ${ }^{[5]}$ An increase in market power would reduce this effect by reducing competition. Overall, the market power effect would predict a higher operating margin for hospitals absorbing patients from closing hospitals.

A second economic force that would benefit surrounding hospitals financially is the occupancy rate effect, which occurs when hospitals are able to reduce excess capacity by filling more hospital beds after a neighbor closes. The cost of an unused hospital bed is high and some researchers have suggested that allowing hospitals' occupancy rates to increase could increase efficiency. ${ }^{[6]}$ Another group of researchers conducted a welfare analysis of hospital closures and measured the benefits of hospital closures primarily through the reduction in excess capacity. ${ }^{[7]}$ They found that cost savings from the reduction in excess capacity outweighs patient costs of increased distances to drive to their nearest hospital. Similar to the occupancy rate effect is the increased demand effect, which says that hospitals will benefit from absorbing new patients even if they increase hospital beds at the same time. Both effects predict a positive impact on hospitals' operating margins from absorbing new patients from closing hospitals. 
Table 1. Summary of hypotheses and effects of hospital closures on surrounding hospitals

\begin{tabular}{|c|c|c|}
\hline Hypothesis/Effect & $\begin{array}{l}\text { Financial impact of } \\
\text { neighboring hospital } \\
\text { closing }\end{array}$ & Ways of testing empirically \\
\hline Market power effect & Positive & $\begin{array}{l}\text { Is there a positive effect on financial status associated with an increase in a hospital's HHI } \\
\text { due to closure? }\end{array}$ \\
\hline Occupancy rate effect & Positive & $\begin{array}{l}\text { Is there a positive effect on the financial status associated with an increase in the occupancy } \\
\text { rate in a hospital due to nearby closures? }\end{array}$ \\
\hline Increased demand effect & Positive & $\begin{array}{l}\text { Is there a positive change in financial success apart from the HHI, occupancy rate, and other } \\
\text { important controls? }\end{array}$ \\
\hline Revenue effect & Negative & $\begin{array}{l}\text { Is there a negative financial shock associated with absorbing more patients? Is that negative } \\
\text { shock associated with a shift toward less profitable payers (e.g. more Medi-Cal and fewer } \\
\text { privately insured) }\end{array}$ \\
\hline Sick patient effect & Negative & $\begin{array}{l}\text { Is there a negative financial shock associated with absorbing more patients? Is this negative } \\
\text { shock unassociated with any shift in payer mix? }\end{array}$ \\
\hline Market condition effect & Negative & Do negative financial shocks appear in surrounding hospitals before the hospital has closed? \\
\hline
\end{tabular}

The only study besides ours to look directly at the impact of hospital closures on surrounding hospitals focuses on the occupancy rate effect and finds it to be substantial. ${ }^{[8]}$ They documented an overall financial benefit for hospitals within five miles of closing hospitals, mainly due to the reduction in excess capacity. Our study differs in that we use patient flow data at the 5-digit zip code level and DRG-level instead of distance to quantify the impact of a hospital closure on surrounding hospitals. We also use data from the 2000's as opposed to the mid-1990's. Since hospitals have likely improved in efficiency since the 1990's, we expect to measure a smaller occupancy rate effect than previous research.

In opposition to the market power effect, occupancy rate effect and increased demand effect, two other forces suggest that hospitals may actually suffer financially when a nearby hospital closes. The first of these is the revenue effect, which happens if the closing hospitals served more patients with less generous insurance. The literature has found an increased probability of closure for hospitals serving populations with less generous insurance reimbursement. ${ }^{[9,10]}$ Also, a hospital has a greater risk of closing if it serves a higher share of people in poverty. ${ }^{[11]}$

Another effect, the sick patient effect, could also cause lower profit margins for absorbing hospitals. This effect arises because of the vast variation in the cost of treating patients with the same reimbursable condition. If a hospital treats an unusually high share of patients on the high end of the cost spectrum, conditional on reimbursement, then it will persistently fail to cover its costs. This problem could be particularly dramatic if there is community-level correlation in patient expenses conditional on illness and risk type. Doctors and consulting firms have conducted investigations that reveal certain neighborhoods, and even certain apartment complexes, produce a disproportionate share of the highest cost patients. ${ }^{[12]}$ These patients often come with many complex chronic conditions and socioeconomic hardships. If cultural characteristics are important in treatment costs, then there may be correlation between a patient's community and where they fall on the cost spectrum. Literature has documented the importance social connectedness in determining a population's health. ${ }^{[13]}$ Cultural competency in providers may also have a positive impact on health. One review of the literature showed that patients sometimes fare better when their health care providers are trained in cultural competency and other times there is no effect. ${ }^{[14]}$ A population with greater needs for cultural competency may also be more expensive to treat, holding all else equal. Finally, low-income people are generally sicker than the average population. ${ }^{[9]}$ The fact that these elements have an effect on health will likely mean that geographic clustering by socioeconomic status, community social connectedness and culture may exacerbate the sick patient effect.

Finally, the market condition effect says that closing hospitals may suffer from unprofitable market conditions that may also impact the surrounding hospitals. Since hospitals generally close after several years of financial struggles, looking at the financial condition of the top absorbers in the years leading up to hospital closures, before they had absorbed any patients, will be important in determining if all hospitals in this market were subject to shocks that had nothing to do with the patients being absorbed.

It is also worth noting that which effect dominates may depend on the for-profit status of the hospitals in the market. It is possible, for example, that not-for-profit hospitals may be more vulnerable to the sick-patient and revenue-effects, while for-profit hospitals are more able to avoid those effects or to better utilize increases in market power. 


\section{Methodology}

\subsection{Data and variables}

We employ data from California's Office for Statewide Health Planning and Development (OSHPD) for the years 2000 to 2011. Hospitals in California report this information annually to the state government. The patient discharge data contains a record of every patient discharged from a California hospital, including that patient's 5-digit zipcode and DRG. The zipcode and DRGs were instrumental for predicting where patients from closing hospitals would go when that hospital closed. OSHPD's hospital financial data set provided annual data on hospitals' total operating revenue and expenses, which were necessary for our main response variable. Finally, the utilization data set contained information about the number of licensed beds and other hospital characteristics, which were important covariates to include in our analysis.

The characteristics of the closing hospitals that we focus on are important to understand. We chose 2004, 2007, and 2009 due to the large number of closures those years, as shown in Figure 1. Table 2 shows summary statistics for the main control variables for three categories of hospitals: (a) closing hospitals, (b) hospitals predicted to absorb patients from those closing hospitals, and (c) hospitals not predicted to absorb many patients from the closing hospitals. Most hospital characteristics do not differ substantially across the top and bottom absorbers (absorbers and non-absorbers). The heavy absorbers are somewhat larger on average than most hospitals, but not by a large amount. They also operate in more competitive markets, as indicated by the HHI, which is a measure of market concentration that is higher for more concentrated markets.

The hospital's operating margin was the main dependent variable. A hospital's operating margin is defined as:

$$
\frac{\text { operatingrevenue - operatingcosts }}{\text { operatingrevenue }}
$$

Where we get the total operating revenue by adding net patient revenue to other operating income. Operating margin has been a common measure of financial success used in both past academic literature ${ }^{[15]}$ and policy discussions. ${ }^{[16]}$

It was necessary for the main independent variable to be a measure of how intensely a hospital was impacted by nearby hospital closures. For this, we calculated the predicted percent increase in patient volume due to absorption of patients from the hospitals that closed in 2004, 2007 and 2009, respectively. The purpose of constructing a prediction was to isolate the impact of absorption from other factors that influence variation in hospitals' patient flow from year to year. Our predictions were based on patient flow data using patient's 5-digit zip code and DRG (or MS-DRG for the 2009 closures). When constructing this prediction, patients in closing hospitals were distributed to open hospitals based on the assumption that historical patient proportions remain the same. For example, there might be a zip code where 600 pneumonia patients $(\mathrm{DRG}=391)$ went to Jewish Hospital, 400 pneumonia patients went to Baptist Hospital and 100 pneumonia patients went to Mercy Hospital in 2003. If Mercy were to close, then Jewish Hospital would experience a 60 patient increase and Baptist would experience a 40 patient increase in pneumonia patients by 2005 , according to our prediction methodology.

This methodology for predicting patient distribution when a hospital closes allows us to capture forces besides proximity that might influence which hospital a patient chooses. One study demonstrated that characteristics besides proximity, such as hospital size and technologies available, motivate which hospitals patients choose. ${ }^{[17]}$ We used percent increase in patients from closing hospitals rather than the raw number of patients absorbed because small hospitals absorbing 200 patients might be greatly impacted financially by the wave of new patients while large hospitals absorbing the same number would not expect to see a major financial change.

We validated this methodology by comparing post-closure patient volumes to predicted patient volumes both with and without absorption. The predictions that included absorption from closing hospitals were closer to the actual patient volumes. This also indicated that capacity constraints were not likely to be a major driver stopping hospitals from absorbing patients from closing hospitals. However, it is also worth noting that even if hospitals had major capacity constraints, the sick patient effect and revenue effect would not be invalidated by these constraints. For example, if a hospital is at $100 \%$ capacity its payer mix would still become less profitable if patients from closing hospitals show up and are selected randomly to fill the available beds.

Another important consideration was the hospital's ownership type. Particularly, for-profit hospitals may have an incentive to cream skim the best patients, while nonprofits and government-owned hospitals would be more likely to take patients of all insurance types. Therefore, our analysis looks separately at the impact of predicted absorption on for-profit and not-for-profit hospitals. Non-profit hospitals, county or city-owned hospitals, district hospitals and state hospitals are all included in the not-for-profit category. 
Table 2. Summary statistics before and after the hospital closures

\begin{tabular}{|c|c|c|c|c|c|}
\hline & Closing Hospitals & $\begin{array}{l}\text { Absorbing } \\
\text { Hospitals }^{* * * *}\end{array}$ & $\begin{array}{l}\text { Non-absorbing } \\
\text { Hospitals }\end{array}$ & $\begin{array}{l}\text { Absorbing } \\
\text { Hospitals }\end{array}$ & $\begin{array}{l}\text { Non-absorbing } \\
\text { Hospitals }\end{array}$ \\
\hline & Before & Before & Before & After & After \\
\hline \multicolumn{6}{|c|}{ Summary statistics before and after the 2004 hospital closures } \\
\hline $\mathrm{N}$ & 5 & 8 & 404 & 8 & 404 \\
\hline Occupancy rate & $74 \%$ & $67 \%$ & $64 \%$ & $57 \%$ & $63 \%$ \\
\hline Hospital size (patients) & 10,318 & 17,879 & 8,502 & 15,548 & 8,700 \\
\hline HHI-MSA & 22.54 & 91.75 & 242.57 & 80.54 & 268.98 \\
\hline HHI & 39 & 581 & 881 & 594 & 867 \\
\hline Teaching & $20 \%$ & $25 \%$ & $4 \%$ & $22 \%$ & $4 \%$ \\
\hline \% Privately insured & $23 \%$ & $48 \%$ & $32 \%$ & $49 \%$ & $31 \%$ \\
\hline \% Medi-Cal and charity & $41 \%$ & $22 \%$ & $26 \%$ & $20 \%$ & $25 \%$ \\
\hline \% Medicare & $33 \%$ & $26 \%$ & $35 \%$ & $28 \%$ & $36 \%$ \\
\hline \multicolumn{6}{|c|}{ Summary statistics before and after the 2007 hospital closures } \\
\hline $\mathrm{N}$ & 6 & 19 & 357 & 19 & 357 \\
\hline Occupancy rate & $52 \%$ & $60 \%$ & $62 \%$ & $63 \%$ & $64 \%$ \\
\hline Hospital size (patients) & 5,936 & 10,758 & 7,744 & 11,509 & 8,157 \\
\hline HHI-MSA & 4.58 & 14.42 & 312.79 & 18.12 & 311.21 \\
\hline HHI & 87 & 252 & 937 & 304 & 968 \\
\hline Teaching & $25 \%$ & $11 \%$ & $4 \%$ & $11 \%$ & $4 \%$ \\
\hline \% Privately insured & $26 \%$ & $26 \%$ & $32 \%$ & $25 \%$ & $32 \%$ \\
\hline$\%$ Medi-Cal and charity & $34 \%$ & $36 \%$ & $25 \%$ & $37 \%$ & $25 \%$ \\
\hline \multicolumn{6}{|c|}{ Summary statistics before and after the 2009 hospital closures } \\
\hline $\mathrm{N}$ & 7 & 17 & 389 & 17 & 389 \\
\hline Occupancy rate & $95 \%$ & $54 \%$ & $63 \%$ & $57 \%$ & $61 \%$ \\
\hline Hospital size (patients) & 6,490 & 9,511 & 8,956 & 9,354 & 8,950 \\
\hline HHI-MSA & 5.38 & 1.34 & 314.47 & 1.58 & 313.22 \\
\hline HHI & 2,158 & 230 & 1,121 & 259 & 1,151 \\
\hline Teaching & $14 \%$ & $6 \%$ & $5 \%$ & $6 \%$ & $5 \%$ \\
\hline \% Privately insured & $22 \%$ & $20 \%$ & $32 \%$ & $20 \%$ & $29 \%$ \\
\hline \% Medi-Cal and charity & $7 \%$ & $28 \%$ & $25 \%$ & $29 \%$ & $27 \%$ \\
\hline \% Medicare & $43 \%$ & $41 \%$ & $36 \%$ & $40 \%$ & $37 \%$ \\
\hline \% Medicare & $34 \%$ & $28 \%$ & $36 \%$ & $29 \%$ & $36 \%$ \\
\hline
\end{tabular}

Note. ${ }^{* * * *}$ We define top absorbers as hospitals that were predicted to experience a greater than $5 \%$ increase in patient volume due to absorption from nearby hospital closures. Conversely, the bottom absorbers are those predicted to experience less than a one percent increase in patient volume.

To test the market power effect, the Herfandahl-Hirschman Index (HHI) is a commonly used measure of each hospital's competitive environment, with higher HHI values being associated with less competitive market environments. The HHI is calculated by taking the sum of the squared market shares of each hospital in a market, where the market shares are multiplied by 100 . So, a market with two hospitals each serving $50 \%$ of the market would have an HHI of $50^{2}+50^{2}=$ 5,000 , while a market with 100 hospitals each serving $1 \%$ of the market would have an HHI of 100 . The challenging part of constructing a measure of $\mathrm{HHI}$ is defining a hospital's geographic market. Our primary analysis uses the Metropolitan Statistical Area (MSA) as the market definition, similar to its definition in other published works. ${ }^{[18]}$ An MSA consists of a large city and the surrounding area, defined by the US census taking into account the economic ties within that population. However, as a check, we also used a zip-code-level methodology for calculating a hospital-specific HHI. ${ }^{[19]}$ This methodology involves calculating a zip-code-level HHI, and then taking each hospital's weighted average HHI across all zip codes of patients it serves, weighting according to the proportion of patients served within that zip code.

Other variables in the study came more directly from the data sets. For example, occupancy rate was calculated by dividing total patient days by average beds per day times three hundred sixty five. We chose to categorize Medi-Cal, county indigent and other indigent patients together into one vari- 
able, since these categories are generally poorly reimbursed. Medi-Cal is California's version of Medicaid. Medi-Cal, county indigent and other indigent charity patients make up about $30 \%, 0.5 \%$ and $0.3 \%$ percent of the population in any given year, respectively. So, the majority of the results from this category are driven by Medi-Cal patients.

\subsection{Empirical model}

The analysis employs a random effects model, which is essentially a multiple linear regression model that allows us to adjust for the fact that different hospitals have different base operating margins. We chose the random effects model over other alternatives because we wanted to account for systematic differences across hospitals without needing to know more detailed information about specific hospitals. Random effects models are more powerful and more generalizable when many hospitals are being studied. Still, a Hausman test with the analogous fixed effects model revealed that the two methodologies produce similar results. The random effects empirical model for 2004 closures is as follows:

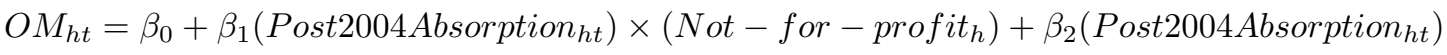

$$
\begin{aligned}
& \times\left(\text { For }- \text { profit }_{h}\right)+\beta_{3} X_{h t}+\beta_{4} Y_{h}+\beta_{5} Z_{t}+\varepsilon_{h} t+\varepsilon_{h}
\end{aligned}
$$

where OM is operating margin; Post2004Absorption is a variable with the predicted percent increase in patient volume for all years after 2004, and zero for all years up through 2004; Not-for-profit and for-profit are dummy variables used as interaction terms $X_{h t}$ is a vector of hospital controls for factors that change over time. This includes occupancy rate, HHI, percent privately insured and percent Medi-Cal/charity; $Y_{h}$ is an indicator variable for whether the hospital is teaching; $Z_{t}$ is a vector of dummy variables for each year.

This equation helped us predict the operating margin for hospital $h$ in time $t$. The main independent variable of interest is Post2004Absorption, because it captures the degree of impact on operating margin that each hospital expects from the hospital closures. We used not-for-profit and for-profit interaction terms with this variable to capture the differential effect of absorption on the two different hospital types. A positive coefficient on Post2004Absorption indicates that hospitals predicted to absorb more patients from 2004 closures experienced a positive financial shock following absorption of those patients. A negative coefficient would indicate a drop in operating margin following the absorption of these patients. We conducted the same analysis for the years 2007 and 2009.

Occupancy rate, hospital size and HHI were the most important controls because of findings in the past literature. Hospital size has been documented as having a consistent impact on financial wellbeing, with larger hospitals enjoying higher operating margins. ${ }^{[15]}$ Reduction in excess capacity has been the focus of hospital optimization problems designed to improve efficiency. ${ }^{[20]}$ Hospital size was logged for this analysis.

To test the market power and occupancy rate effects, we ran the same model except using HHI and occupancy rate as the dependent variables instead of operating margin. This would give us a measure of the degree to which absorption of patients from closing hospitals impacted market power and occupancy for the top absorbers. Similarly, we moved percent private and percent Medi-Cal/charity to the left side of the equation to capture changes in payer mix that may have been due to absorption, and to test the revenue effect. These steps helped us discern how much absorption of new patients was influencing HHI, occupancy rates and payer mixes within the hospital. To test for the market condition effect, we looked at operating margins in our top and bottom absorbing hospitals both before and after hospital closures (see Figure 2).

\section{ReSUlts}

Our main finding best supports the sick patient effect, or the notion that closing hospitals distribute high-cost patients to open not-for-profit hospitals. Not-for-profit hospitals that were predicted to absorb more patients from closing hospitals experienced a negative overall financial shock after the hospitals closed, as shown in Table 3. For-profit hospitals, however, do not appear to be impacted in the same way by absorbing patients from closing hospitals. For all three years of closure, there is no significant relationship between absorbing patients and hospital operating margin in for-profit hospitals.

We can reject the idea that an unfavorable shift in a hospital's percent Medi-Cal and privately insured patients is driving this negative financial shock, according to Table 4 . The first column in Table 4 shows regression on percent Medi-Cal and charity as dependent variables, with absorption of patients as the important independent variable. The fact that the coefficients on absorption are insignificant demonstrates that the hospitals did not experience a change in their percent Medi-Cal or percent privately insured after absorbing new patients. The implication is that the drop in profitability for 
these not-for-profit hospitals must be due to a rise in costs conditional on reimbursement, rather than a worsening of payer mix. It is therefore reasonable to dismiss the revenue effect as the driver behind the decline in operating margins.

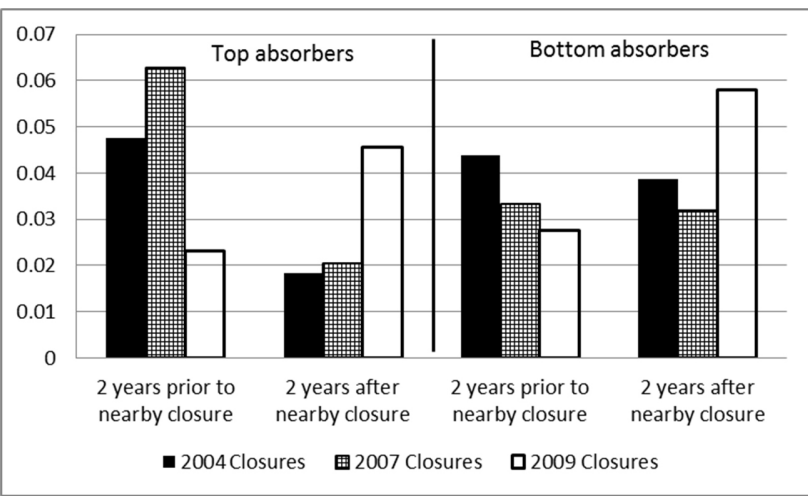

Figure 2. Operating Margin at top and bottom absorbing hospitals before and after the hospital closures

On the other hand, Table 4 indicates that for-profit hospitals saw a favorable change in the payer mix of their patients when absorbing from closing hospitals, as indicated by the positive and statistically significant coefficients. This change in payer mix may explain why for-profit hospitals did not experience the same negative financial shock as not-for-profits.
Table 5 demonstrates that absorbing patients from closing hospitals does not improve a hospital's competitive environment or increase its market power, as measured by the HHI. HHI is a measure of market concentration, and we have conducted the analysis regressing on both a broad market definition (MSA-level HHI) and also regressing on a hospitalspecific HHI. Like with all of our tables, we conducted the analysis separately for 2004, 2007 and 2009 closures. All but one of the six regressions reveals no statistically significant relationship between absorption of patients from closing hospitals and HHI. Even though one of the two HHI measures is significant for the 2009 hospital closures, its coefficient is negative, which indicates that competition increased after the hospitals absorbed patients from closing hospitals, which is in the opposite direction of the prediction of the market power hypothesis. Therefore, we find no evidence that absorption of patients from closing hospitals increases market power for absorbing hospitals. This finding is not surprising, given that the models predict only a 10\%, 15\% and $7 \%$ increase in patient volume for the top ten absorbers for the 2004, 2007 and 2009 closures respectively, and that these hospitals generally already operate in fairly competitive markets (see Table 2). Based on this evidence, the market power effect is not a major driver in operating margins for hospitals absorbing patients from closing hospitals.

Table 3. Regressing on hospitals' operating margins using a random effects model, including dummy variables for after the relevant hospital closures

\begin{tabular}{llll}
\hline & $\begin{array}{l}\text { Absorption associated w/2004 } \\
\text { closures }\end{array}$ & $\begin{array}{l}\text { Absorption associated w/2007 } \\
\text { closures }\end{array}$ & $\begin{array}{l}\text { Absorption associated w/2009 } \\
\text { closures }\end{array}$ \\
\hline $\begin{array}{l}\text { (\% increase from closure absorption) } \\
\times(\text { Not-for-profit) } \times(\text { After })\end{array}$ & $-.79^{* * *}$ & $-.76^{* * *}$ & $-.97^{* *}$ \\
$\begin{array}{l}\text { \% increase from closure absorption) } \\
\times(\text { For-profit }) \times(\text { After })\end{array}$ & .14 & .40 & $.87^{* *}$ \\
For-profit dummy & .02 & .02 & .01 \\
Occupancy rate & $.20^{* * *}$ & $.22^{* * *}$ & $.22^{* * *}$ \\
Hospital size & $.02^{* * *}$ & $.02^{* * *}$ & $.02^{* * *}$ \\
HHI-MSA & $.00001^{* * *}$ & $.00001^{* * *}$ & $.00001^{* * *}$ \\
Teaching dummy & .003 & .01 & .01 \\
$\%$ privately insured & $.09^{* * *}$ & $.09^{* * *}$ & $.07^{* *}$ \\
$\%$ Medi-Cal and charity & $-.06^{* *}$ & $-.06^{* *}$ & $-.07^{* *}$ \\
$\mathrm{~N}$ & 3,077 & 3,033 & 3,139 \\
\hline$* * * *$
\end{tabular}

${ }^{* * *}=$ Statistically significant at the .01 level; ${ }^{* *}=$ Statistically significant at the .05 level

The top absorbers also did not experience major changes in their occupancy rates following the closure of nearby hospitals. When using occupancy rate as the dependent variable (see Table 5), the coefficient on post-closure absorption is not statistically significant, so it is reasonable to dismiss the occupancy rate effect as a major driver behind the financial impact of hospital closings on surrounding hospitals.
The small change in occupancy is likely due to the fact that absorbing hospitals seem to have expanded capacity to accommodate the incoming patients. For example, the top absorbers of 2004 and 2007 closures (hospitals expected to experience over a $5 \%$ increase in patient volume due to absorption) both had an increase in beds that was double the average increase in beds among non-absorbing hospitals 
between the year before and the year after absorption.

The negative financial shock also does not appear to have begun before the nearby hospital closures, indicating that poor market conditions in a region are not driving both the hospital closures and the negative shocks in nearby absorbing hospitals. Figure 2 demonstrates this graphically by showing the operating margins before and after the 2004, 2007 and 2009 hospital closures for the top and bottom absorbing hospitals. For the 2004 and 2007 hospital closures, there is a clear trend indicating that the top absorbers were doing well before the nearby closure, and had a drop in the operating margin afterward. These reasons lead us to reject the market condition effect as the reason for the negative financial shock. In Figure 2, the story for 2009 closures is complicated by the fact that hospital operating margins are increasing across the board for all hospitals during that time period. This increase was smaller for the top absorbers (an increase of .02 instead of .03 for the hospitals not absorbing patients). Our empirical model uses year dummies to account for market-wide trends like this.

Table 4. Regressing on percent Medi-Cal/charity, percent privately insured, and percent Medicare using a random effects model

\begin{tabular}{|c|c|c|c|c|c|c|c|c|c|}
\hline & \multicolumn{3}{|c|}{2004 closures } & \multicolumn{3}{|c|}{2007 closures } & \multicolumn{3}{|c|}{2009 closures } \\
\hline & $\begin{array}{l}\text { Medi-Cal/ } \\
\text { Charity }\end{array}$ & $\begin{array}{l}\text { Privately } \\
\text { Insured }\end{array}$ & Medicare & $\begin{array}{l}\text { Medi-Cal/ } \\
\text { Charity }\end{array}$ & $\begin{array}{l}\text { Privately } \\
\text { Insured }\end{array}$ & Medicare & $\begin{array}{l}\text { Medi-Cal/ } \\
\text { Charity }\end{array}$ & $\begin{array}{l}\text { Privately } \\
\text { Insured }\end{array}$ & Medicare \\
\hline $\begin{array}{l}\text { (\% increase from closure } \\
\text { absorption) } \times \text { (Not-for-profit) } \\
\times(\text { After })\end{array}$ & -.13 & $.27^{*}$ & -.02 & $.23^{* *}$ & .00 & -.02 & .09 & .14 & -.27 \\
\hline $\begin{array}{l}\text { (\% increase from closure } \\
\text { absorption) } \times \text { (For-profit) } \times \\
\text { (After) }\end{array}$ & $-.54^{* * *}$ & $.43^{* *}$ & $.41^{* *}$ & $-.49^{* * *}$ & $-.31^{*}$ & $.90^{* * *}$ & $-.49^{* *}$ & .20 & .31 \\
\hline For-profit dummy & $.02^{* *}$ & $-.04^{* * *}$ & -.01 & $.01^{*}$ & $-.03^{* * *}$ & -.01 & $.01^{*}$ & $-.03^{* * *}$ & .00 \\
\hline Occupancy rate & .01 & $-.03^{* * *}$ & $.03^{* * *}$ & .01 & $-.03^{* * *}$ & $.02^{* *}$ & -.01 & $-.03^{* * *}$ & $.03^{* * * *}$ \\
\hline Hospital size & $-.01^{* *}$ & $.03^{* * *}$ & $-.01^{* * * *}$ & $-.01^{* * *}$ & $.03^{* * * *}$ & $-.01^{* * *}$ & .00 & $.03^{* * *}$ & $-.01^{* * * *}$ \\
\hline HHI-MSA & .00 & .00 & .00 & .00 & .00 & .00 & .00 & .00 & .00 \\
\hline Teaching dummy & .01 & -.02 & -.01 & .01 & -.02 & -.01 & .02 & $-.03^{*}$ & -.01 \\
\hline $\mathrm{N}$ & 3,382 & 3,382 & 3,382 & 3,324 & 3,324 & 3,324 & 3,456 & 3,456 & 3,456 \\
\hline
\end{tabular}

${ }^{* * *}=$ Statistically significant at the .01 level; ${ }^{* *}=$ Statistically significant at the .05 level; ${ }^{*}=$ Statistically significant at the .1 level

These results were robust to various variable changes and specifications of the model. Omitting any particular control variable from our model does not change the results. The results also remain robust when using the zip-code-level methodology ${ }^{[20]}$ for calculating HHI instead of the MSA construction. When omitting the year dummies, the 2004 and 2007 results remain the same. However, the 2009 results are no longer significant without year dummies. Since 2009 was in the middle of an economic downturn that impacted hospital volume and profitability, controlling for cyclical influences was important. All of our results remain the same when using fixed effects instead of random effects, and the Hausman test indicated that there was not a significant difference between these models for the results.

\section{Discussion}

This study faces several limitations. First, we might be imperfectly predicting where populations from closing hospitals would go after their hospital closes. Our prediction methodology relies solely on zip code and DRG data to distribute patients to open hospitals. Other factors such as cultural preferences, distance, and word-of-mouth networks may influence patient decisions as well, and future studies may want to more fully account for those factors. Similarly, capacity constraints may limit nearby hospitals' ability to absorb the patients that we predict. Even though Table 2 indicates that occupancy rates seem similar at absorbing hospitals compared to other hospitals, this may mask seasonal variation that might put hospitals at full capacity. We assume that even if hospitals run up against capacity constraints, they would divert patients randomly. However, this assumption might be subject to criticism, particularly if patients with certain DRGs were more likely to be diverted to other hospitals.

Our results also may not fully account for the market condition effect, particularly if market conditions changed during the year of a hospital closure, rather than before. Figure 2 shows that absorbing hospitals were doing slightly better than other hospitals before the 2004 and 2007 closures, and slightly worse before the 2009 closures. It is possible that the 2004 and 2007 closures happened because of very bad conditions in 2004 and 2007, which were not yet reflected in the 2003 and 2006 data. In which case, the market forces 
that drove these closures might still be negatively influencing hospital operating margin for other hospitals in their markets.

Another limitation has to do with the broadness of the application of our result. These results suggest that an unlucky mix of patients, those who are expensive conditional on reimbursement, may be causing or exacerbating hospital financial struggles. This result stands in contrast to the idea that poor management alone accounts for hospital financial struggles. However, our result does not preclude the notion that hospital closures may be a movement toward efficiency. Even if open hospitals experience an increase in expenses per patient when taking in closed hospitals' patients, it is possible that they still treat the patients less expensively than the closed hospitals.

Table 5. Regressing on HHI and Occupancy Rate using a random effects model, 2004, 2007 and 2009 closures

\begin{tabular}{|c|c|c|c|c|c|c|c|c|c|}
\hline & \multicolumn{3}{|c|}{2004 closures } & \multicolumn{3}{|c|}{2007 closures } & \multicolumn{3}{|c|}{2009 closures } \\
\hline & HHI-MSA & $\begin{array}{l}\text { HHI- } \\
\text { Zwanziger }\end{array}$ & $\begin{array}{l}\text { Occupancy } \\
\text { Rate }\end{array}$ & HHI-MSA & $\begin{array}{l}\text { HHI- } \\
\text { Zwanziger }\end{array}$ & $\begin{array}{l}\text { Occupancy } \\
\text { Rate }\end{array}$ & HHI-MSA & $\begin{array}{l}\text { HHI- } \\
\text { Zwanziger }\end{array}$ & $\begin{array}{l}\text { Occupancy } \\
\text { Rate }\end{array}$ \\
\hline $\begin{array}{l}\text { (\% increase } \\
\text { from closure } \\
\text { absorption) } \\
\times \text { (After) }\end{array}$ & -228 & 776 & .31 & -76 & 312 & -.15 & -4726 & $-15621^{* * *}$ & $-1.20^{* *}$ \\
\hline For-profit & -57 & $-75^{* *}$ & $-.03^{* *}$ & -68 & $-88^{* *}$ & -.01 & -72 & $-77^{* *}$ & -.01 \\
\hline $\begin{array}{l}\text { Occupancy } \\
\text { rate }\end{array}$ & 53 & 52 & & 60 & 15 & & 34 & 67 & \\
\hline Hospital size & $107^{* * *}$ & $214^{* * *}$ & $.03^{* * *}$ & $110^{* * *}$ & $209^{* * *}$ & $.04^{* * *}$ & $118^{* * *}$ & $227^{* * *}$ & $.04^{* * *}$ \\
\hline HHI-MSA & & & .00 & & & .00 & & & .00 \\
\hline $\begin{array}{l}\text { Teaching } \\
\text { dummy }\end{array}$ & 6 & 86 & .02 & 11 & 120 & .02 & -78 & 60 & .01 \\
\hline $\begin{array}{l}\text { \% Privately } \\
\text { insured }\end{array}$ & -97 & -24 & $-.10^{* * *}$ & -47 & 64 & $-.09^{* * *}$ & -54 & 53 & $-.10^{* * *}$ \\
\hline $\begin{array}{l}\text { \%Medi-Cal/ } \\
\text { Charity }\end{array}$ & -48 & 16 & -.03 & 65 & 148 & -.01 & 138 & $199^{* *}$ & -.02 \\
\hline $\mathrm{N}$ & 3,382 & 2,486 & 3,382 & 3,324 & 2,453 & 3,324 & 3,345 & 2,451 & 3,345 \\
\hline
\end{tabular}

= Statistically significant at the .01 level; ${ }^{* *}=$ Statistically significant at the .05 level

\section{Conclusion}

When a not-for-profit hospital absorbs patients from closing hospitals, our findings show that the absorbing hospital will generally experience a negative financial shock. However, payer type, occupancy and HHI (the hospital's competitive environment) do not seem to be driving this effect. The implication is that the closing hospitals served a group of patients who were more expensive, conditional on reimbursement. Since information on payer mix is readily available, policymakers often take into consideration a disadvantageous payer mix when evaluating financial performance. The fact that payer mix is not driving the result indicates that the cost side of financial burden may be underappreciated in influencing financial hardship.

In contrast to not-for-profit hospitals, for-profit hospitals do not experience a negative financial shock. Instead, forprofit saw an improvement in payer mix when absorbing patients from closing hospitals; they had an increase in percent privately insured and a decrease in percent on Medi-Cal, California's version of Medicaid. Whether the for-profit hospitals are intentionally cream skimming the best patients from closing hospitals is not addressed in this paper.
The Affordable Care Act will bring new populations into the hospital system. If those new populations are higher cost, conditional on reimbursement, then some hospitals may begin to experience financial difficulties. Policymakers should be careful not to assume that efficiency and management problems are the only forces leading to financial struggles for hospitals. Also, policymakers should be more aware of impending negative effects on remaining hospitals when some are allowed to close. Finally, government decisions to bail out hospitals may need to take into account the cost distribution of treating a particular population of patients, not just the payer mix of that group.

Another implication of this research is that a lack of good data on the underlying cost of treating specific populations may hinder the ability of administrators and governments to assess the true cause behind hospital financial failures. The fact that these patients become a financial burden to hospitals wherever they go indicates that reimbursement schemes do not fully adjust for some important factors when considering the cost of treating different patients. If insurers and policymakers want to promote a system that rewards well-managed hospitals, they may need to focus more energy on adjusting 
reimbursement to more closely align with the cost of treating specific populations of patients.

In the past, economists and policymakers have speculated that hospital closures may promote efficiency through a survival-of-the-fittest principal. However, evidence presented here demonstrates that surviving hospitals are hurt financially when they absorb patients from closing hospitals. Independent of management, the populations served by closing hospitals may burden any hospital financially, regardless of management quality. These findings suggest that an unlucky mix of patients may be at least partially responsible for hospital closures, and that these patients will burden the system wherever they appear.

\section{REFERENCES}

[1] Dong GN. Performing well in financial management and quality of care: evidence from hospital process measures for treatment of cardiovascular disease. BMC Health Services Research. 2015; 15: 45. PMid: 25638252. http://dx.doi .org/10.1186/s12913-0 15-0690-x

[2] Ianni S. Hospital Alliance of New Jersey. Hospital Alliance's testimony before the Commission on Rationalizing Health Care Resources. 2007. Available from: http://www.nj.gov/healt $\mathrm{h} / \mathrm{rhc} /$ documents/hosptial_alliance_testimony.pdf. Accessed March 26, 2015.

[3] Sagar A, Socolar D, Deol J. Access and Affordability Monitoring Project. Before it's too late: why hospital closings are a problem, not a solution. Early findings from the Massachusetts Hospital Reconfiguration Study. 2nd ed. Boston: Boston University School of Public Health; 1997.97 p.

[4] Gaynor M, Town RJ. Competition in health care markets. No. w17208. National Bureau of Economic Research, 2011. http: //dx.doi.org/10.3386/w17208

[5] Li H, Gail MH, Braithwaite SR, et al. Are hospitals "keeping up with the Joneses"? Assessing the spatial and temporal diffusion of the surgical robot. Healthcare. 2014; 2: 152-157. http: //dx.doi.org/10.1016/j.hjdsi.2013.10.002

[6] Litvak E, Bisognano M. More patients, less payment: Increasing hospital efficiency in the aftermath of health reform. Health Affairs 2011; 30: 76-80. PMid: 21209441. http://dx.doi.org/10.13 $77 /$ hlthaff. 2010.1114

[7] Capps C, Dranove D, Lindrooth RC. Hospital closure and economic efficiency. Journal of Health Economics. 2010; 29: 87-109. PMid: 20004489. http://dx.doi.org/10.1016/j.jhealeco. 2009.10.006

[8] Lindrooth RC, Lo Sasso AT, Bazzoli GJ. The effect of urban hospital closure on markets. Journal of Health Economics. 2003; 22: 691 712. PMid: 12946454. http://dx.doi.org/10.1016/S0167-6 296 (03) 00060-2

[9] Hsia RY, Srebotnjak T, Kanzaria HK, et al. System-level health disparities in California emergency departments: minorities and Medicaid patients are at higher risk of losing their emergency departments. An- nals of emergency medicine. 2012; 59: 358-365. PMid: 2093435. ht tp://dx.doi.org/10.1016/j.annemergmed.2011.09.018

[10] Bazzoli GJ, Lee W, Hsieh HM, et al. The effects of safety net hospital closures and conversions on patient travel distance to hospital services. Health services research. 2012; 47: 129-150. PMid: 22091871. http://dx.doi.org/10.1111/j.1475-6773.2011.01318.x

[11] Hsia RY, Kellermann AL, Shen YC. Factors associated with closures of emergency departments in the United States. JAMA: The Journal of the American Medical Association. 2011; 305: 1978-1985. PMid: 21586713. http://dx.doi.org/10.1001/jama.2011.620

[12] Gawande A. The hot spotters. New Yorker. 2011; 41.

[13] Hawkley LC, Cacioppo JT. Social Connectedness and Health. Human Bonding: The Science of Affectional Ties. 2013; 343.

[14] Lie DA, Lee-Rey E, Gomez A, et al. Does cultural competency training of health professionals improve patient outcomes? A systematic review and proposed algorithm for future research. Journal of general internal medicine. 2011; 26: 317-325. PMid: 20953728. http://dx.doi.org/10.1007/s11606-010-1529-0

[15] Bazzoli GJ, Chen HF, Zhao M, et al. Hospital financial condition and the quality of patient care. Health Economics. 2008; 17: 977-995. PMid: 18157911. http://dx.doi.org/10.1002/hec.1311

[16] Waltman S. Greater New York Hospital Association. Testimony of Greater New York Hospital Association before the New York City Council Committee on Health at a hearing on hospital closures. 2005.

[17] Escarce JJ, Kapur K. Do Patients Bypass Rural Hospitals? Determinants of Inpatient Hospital Choice in Rural California. Journal of health care for the poor and underserved. 2009; 20: 625-644. PMid: 9648694. http://dx.doi.org/10.1353/hpu.0.0178

[18] Sabik LM. The effect of community uninsurance rates on access to health care. Health services research. 2012; 47: 897-918. PMid: 22172046. http://dx.doi.org/10.1111/j.1475-6773.2011 $.01364 . \mathrm{x}$

[19] Zwanziger J, Melnick GA, Mann JM. Measures of hospital market structure: a review of the alternatives and a proposed approach. Socioeconomic planning sciences. 1990; 24: 81-95. PMid: 10108912.

[20] Rais A, Viana A. Operations research in healthcare: a survey. International Transactions in Operational Research. 2011; 18: 1-31. http://dx.doi.org/10.1111/j.1475-3995.2010.00767.x 